\title{
What is the most important in children's education?
}

\author{
Jingzhou An \\ School of Management, Tianjin University of Technology, Tianjin, 300384, China \\ angelcando@163.com
}

\begin{abstract}
It is frequent to see more and more children behave rudely to others especially their parents in public places and hardly pay any passion and effort on their study these days. Someone may say this is the failure of education. This paper intends to find the reason why this kind of phenomenon becomes more and more frequent according to research three important factors closely associated with children's education, which are social education, family education and school education. At last, we concluded that family education is the most important in children's education and we suggest some advice to help parents educate their children.
\end{abstract}

Keywords: children's education; social education; family education; school education.

\section{Introduction}

These days, more and more children becomes disgusted with study and they behave impolite to their parents and other elder people. They don't have dreams and just live boringly. Some of them may be addicted into computer games without caring how much they paid for the games. They just buy anything they like, never think about how difficult and tired it is that their parents make the money. The reason why this phenomenon appears must be related to the way of education, which including social education, family education and school education. Education doesn't only mean the knowledge, but also mean the morality which lead our way of doing things and becoming a good person. In this paper, the education we discuss is mainly about morality

\section{Literature References}

Family education, social education and school education have been a hot topic these years. Liu Qian et al [1] research on the interactive cultural mechanism between family education and school education. Wang Lei [2] researches on the development and basic experience of education of modern society of China. Zhang Honghua[3]studies the cooperation of family education, school education and social education. Zhang Yong [4] thinks the inevitable path of forming resultant force of family and school is from communication to cooperation. Cai Guanglin [5] researches on the aim and strategy of parents on family education.

\section{Research on the three kinds of education}

\subsection{Family education}

Family education places an important role in children's education. So parents should pay more attention on the way of education. More and more parents have the wrong concept that they have to earn more money to make their children live happily. So they are busy working every day and let the baby-sitter take care of their children or even leave them alone. Like the scene in fig1.When their children make mistakes, they would beat or scold them without any communication as they believe their children don't understand their tiredness and hard work. In this way, the children cannot feel the love from their parents even they may complain or hate their parents scold or beat them, and hardly accompany with them. That's why we can usually see a lot of children quarrel with their parents with their eyes full of hatred. We suggest that parents should spend more time on the education of their children and they should firstly control their own bad behaviors before their children instead of beating them for bad behaviors. Just like the scene in Fig 2, if the parents can't set an example for their children, they won't have the qualification to teach their children. [6] 


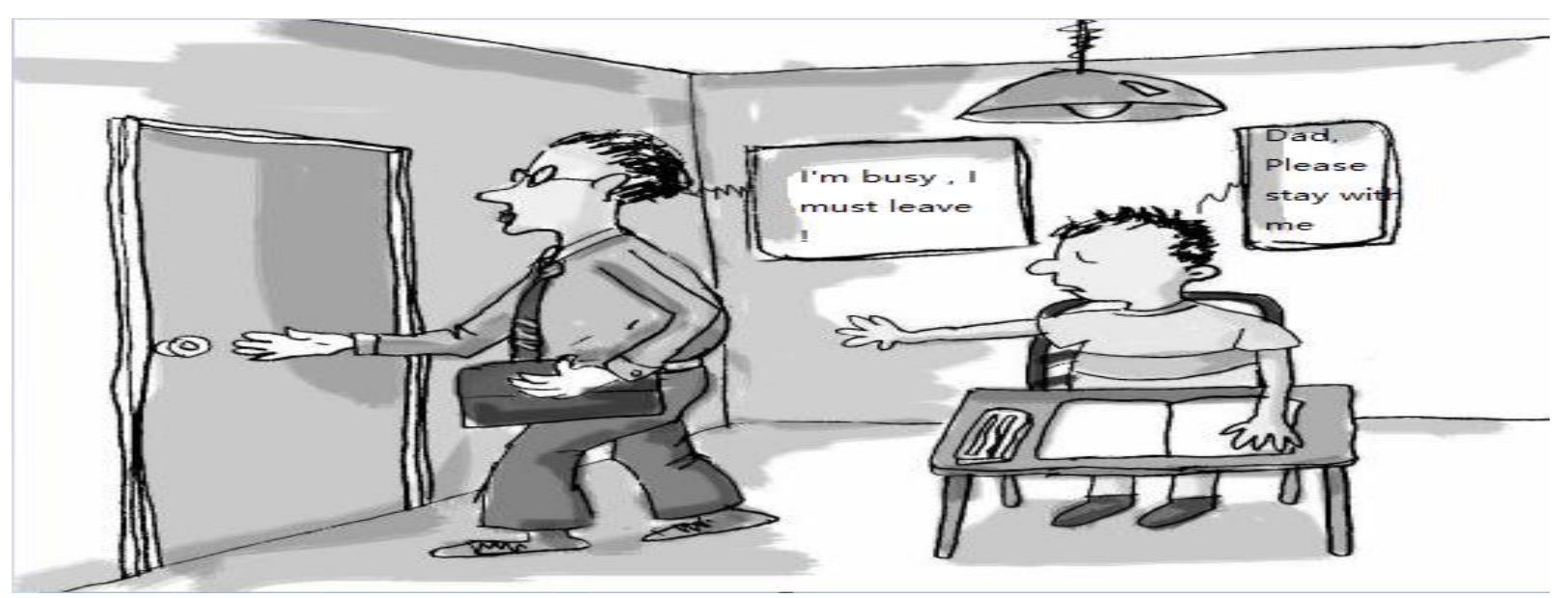

Fig 1.Accompany with children

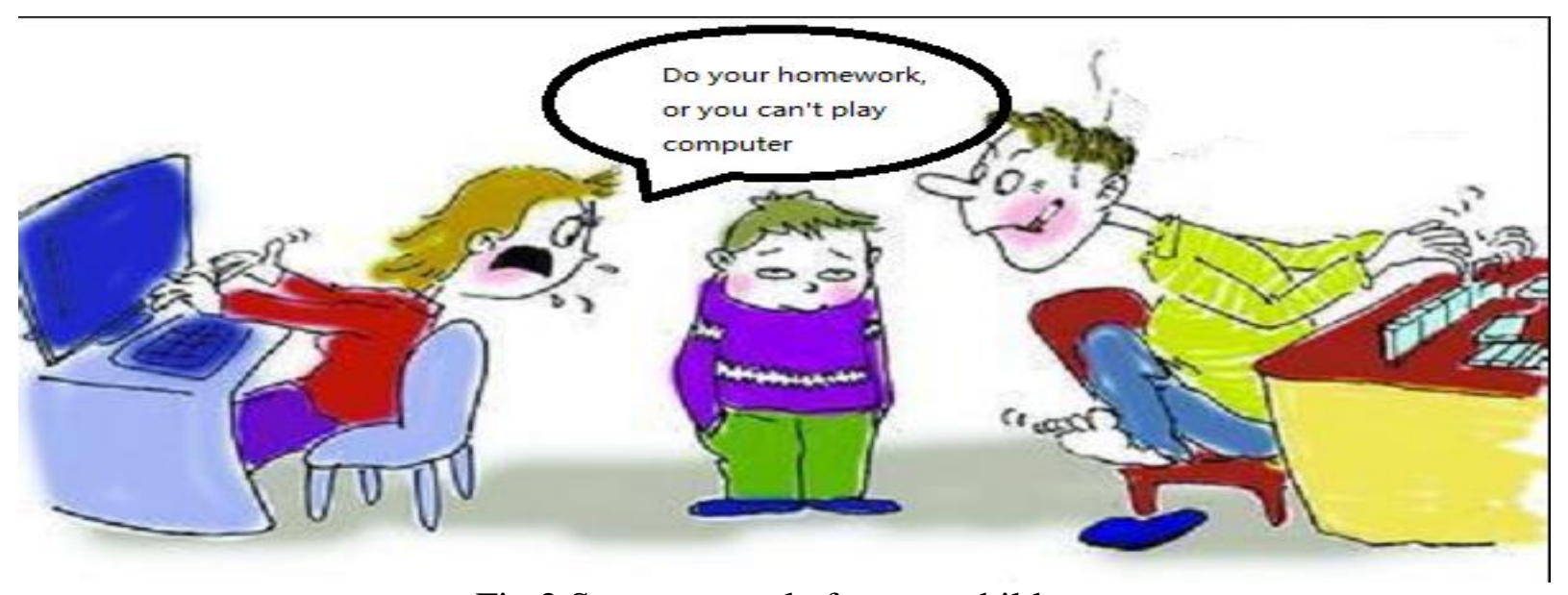

Fig 2.Set an example for your children

\subsection{Social education}

Social education has the potential effect on children's education. Children are curious about almost anything they meet every day. The children we see who are fighting or smoking may learn from the people they meet in the street or somewhere else. So we suggest that our government should do something to improve the level of civilization of our society. Such as building more museums [7] which school can organize students to visit, playing some meaningful movies on the playground or in the park to attract and teach children, putting up some posters about good behaviors or protecting our environment on public walls to give children potential influence and so on. In a word, there are many ways that social can give children good education.

\subsection{School education}

It doesn't need to say that school is an important place for children to study. But most of the schools just pay attention to the academic record. They seldom organize activities or open some lessons about morality. So that we can see more and more children confirm with "high marks but poor competence" or hate study.

\section{The combination of the three kinds of education}

All of the three kinds of education are important for children, while, if we want to meet a better result of education, we should try to combine them $[8,9]$.

\subsection{The combination of family education and school education}

Parents should often communicate with school teachers to know their children's appearance at school and match up with teacher to correct their children's disadvantages [10]. 


\subsection{The combination of family education and social education}

Parents should often bring their children to the museums and explain to their children the meaning of the pictures or words in the museum and should explain the positive meaning of the posters or phenomenon their children see in the street. In this way, they can cultivate their children to think and learn everywhere not just in the school or in the study.

\subsection{The combination of social education and school education}

School should organize more activities such as planting trees, helping poor old people and so on, during these activities, children will learn something different from the knowledge in the textbooks and they will set up friendship with more classmates. And they also can understand the hardship of life. This can also arouse children's sympathy. They will feel tired but happy during this. Just like the scene in the Fig 3 [11].

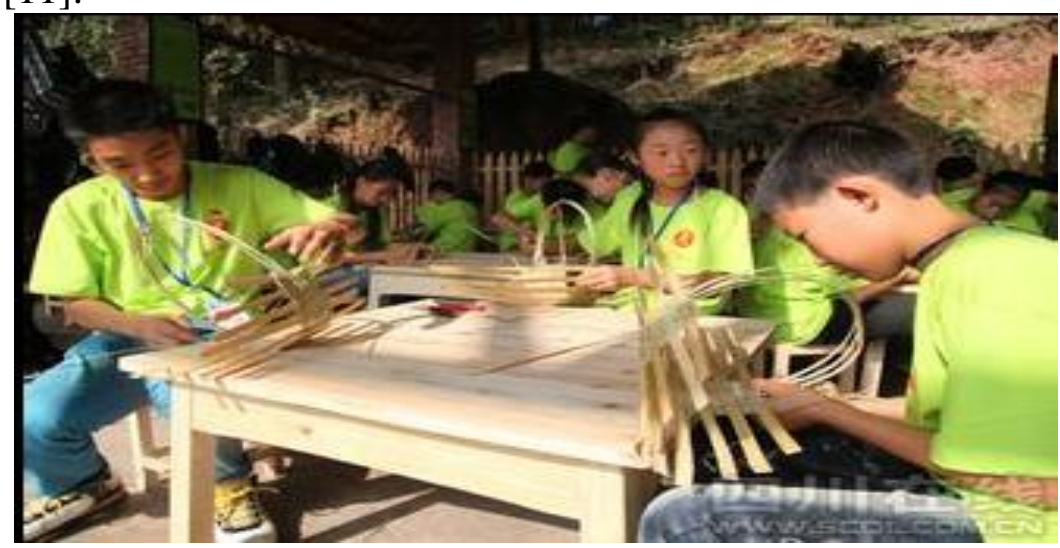

Fig3. School activities

\section{Summary}

So what is the most important in children's education? After discussion above, we know that only if we appropriately combine the family education, school education and social education ${ }^{[9]}$, will the children feel the love from parents, school and society, and grow healthily.

\section{References}

[1] LIU Q, FENG Y, SHENGLONG Q. Pilot exploration on the interactive cultural mechanism between family education and school education. - based on the field work of the migrant's children families' education activities in Beijing. [J]Education Research. Vol. 7(2012) No.390, p.22-28.

[2] WANG L. The development and basic experience of education of modern society of China. [J]Journal of East China Normal University (Educational Science). Vol.28(2010) No.3.p81-86

[3] ZHANG $\mathrm{H}$. The ecological analysis of cooperation of family education, school education and social education.[J] Modern Education Forum.Vol.10(2009).p8-10

[4] ZHANG Y. From communication to cooperation- the inevitable path of forming resultant force of family and school. [J]Education Science Research. Vol.3(2011).p61-64

[5] CAI G L. Discussion on the aim and strategy of parents on family education. [J] Jouranl of Educational Institute of Jilin Province. Vol.28(2012) No.301.p101-103

[6] GUAN Y. Family education method and children's socialization. [J] Social Science of Tianjin.Vol.04 (1994).p107-110.

[7] SHAN Q. The social responsibility and education of museums. [J] Culture of Southeast. Vol. 06(2010).p 9-16.

[8] Information on : http://www.360doc.com/content/14/0224/08/15061035_355176730.shtml 
[9] Information on : http://www.mc.e21.cn/Item/42858.aspx

[10]HUANG H Q. Discussion of the combination of family education and school education. [J] Education Comments. Vol.04 (2001).p 24-27.

[11] Information on: http://image.baidu.com/search/index ?ie=utf- $8 \&$ tn $=$ baiduimage $\&$ word= Family Education 